\title{
THE REGULATION OF ALDOSTERONE SECRETION IN MAN: THE ROLE OF FLUID VOLUME ${ }^{1}$
}

\author{
BY FREDERIC C. BARTTER, GRANT W. LIDDLE, LEROY E. DUNCAN, JR., \\ JOAN K. BARBER, AND CATHERINE DELEA \\ (From The Section of Clinical Endocrinology, National Heart Institute, National Institutes of \\ Health, Public Health Service, U. S. Department of Health, Education, \\ and Welfare, Bethesda, Md.)
}

(Submitted for publication May 4, 1956; accepted August 2, 1956)

Although aldosterone has recently been shown to play a part in the retention of sodium by edematous subjects (5), the factors governing its production have not been defined.

It has been reported (6) that sodium restriction in normal subjects leads to increases in urinary aldosterone-like steroids, and that the quantities of such steroids are, other things being equal, inversely proportional to the amount of sodium excreted in the urine (5). In the studies reported here we have confirmed these reports in part, and have sought to clarify the mechanism or mechanisms by which changes in sodium balance lead to changes in aldosterone secretion. The evidence supports the view that some function of extracellular fluid volume, and not sodium per se, mediates the regulation of aldosterone secretion by dietary sodium.

\section{METHODS}

Studies were done on 18 normal control subjects, on one patient with diabetes insipidus and on one with panhypopituitarism. They were maintained on metabolic regimen, in air-conditioned environment; intake of food and fluids was changed only as the design of experiment required changes of salt and water intake. In four instances, only water, dextrose and sodium chloride were given throughout the study. Body weight was determined daily under standard conditions, and blood drawn at the start of metabolic days. Urine was collected in 24-hour lots. Serum and urine were analyzed for sodium and potassium by flame photometer, with lithium as internal standard, for chloride by the method of Van Slyke and Hiller (7) and for osmolality by the instrument designed by Bowman, Trantham, and Caulfield (8) using as standards sodium chloride solutions corrected for "true" osmolality with the use of the International Critical Tables (9). Urinary aldosteronelike steroids were estimated by bioassay in adrenalectomized dogs by a method previously described (10). For

1 These studies have been reported in part and summarized elsewhere (1-4). reasons defined in that paper, substances so determined are hereinafter referred to as aldosterone.

\section{RESULTS}

\section{The effect of sodium deprivation (Figure 1)}

When dietary sodium was restricted to 10 or less milliequivalents a day there ensued in all cases 1) a loss of weight, 2) an increase of urinary aldosterone and 3) a decrease in urinary sodium excretion. When mercurial diuretics were given as sodium restriction was begun, these changes were brought about within one 24-hour period. They occurred in a patient with panhypopituitarism, and in four normal subjects whose intake consisted of water, glucose and sodium chloride alone. Similar results have been obtained by Luetscher and Axelrad (6) following sodium deprivation and mercurial diuretics and by Beck, Dyrenfurth, Giroud, and Venning following the sodium diuresis produced by Pitressin ${ }^{\circ}$ and water (11). When no further procedure was carried out (see below) the increased excretion of aldosterone persisted until sodium was restored to the diet.

In the sodium-depleted subject, replacement of salt and water resulted in a prompt reversal of the changes described above, that is, in 1) weight gain, 2) a decrease of urinary aldosterone and 3 ) an increase in urinary sodium excretion. These changes are illustrated in Figure 1. The serum sodium concentration did not change significantly with deprivation or with restoration of sodium. Thus, water was lost and regained pari passu with sodium.

\section{The effect of expansion of body fluids}

In order to separate the role of sodium from that of water in the above phenomena, four subjects were depleted of sodium and maintained on 

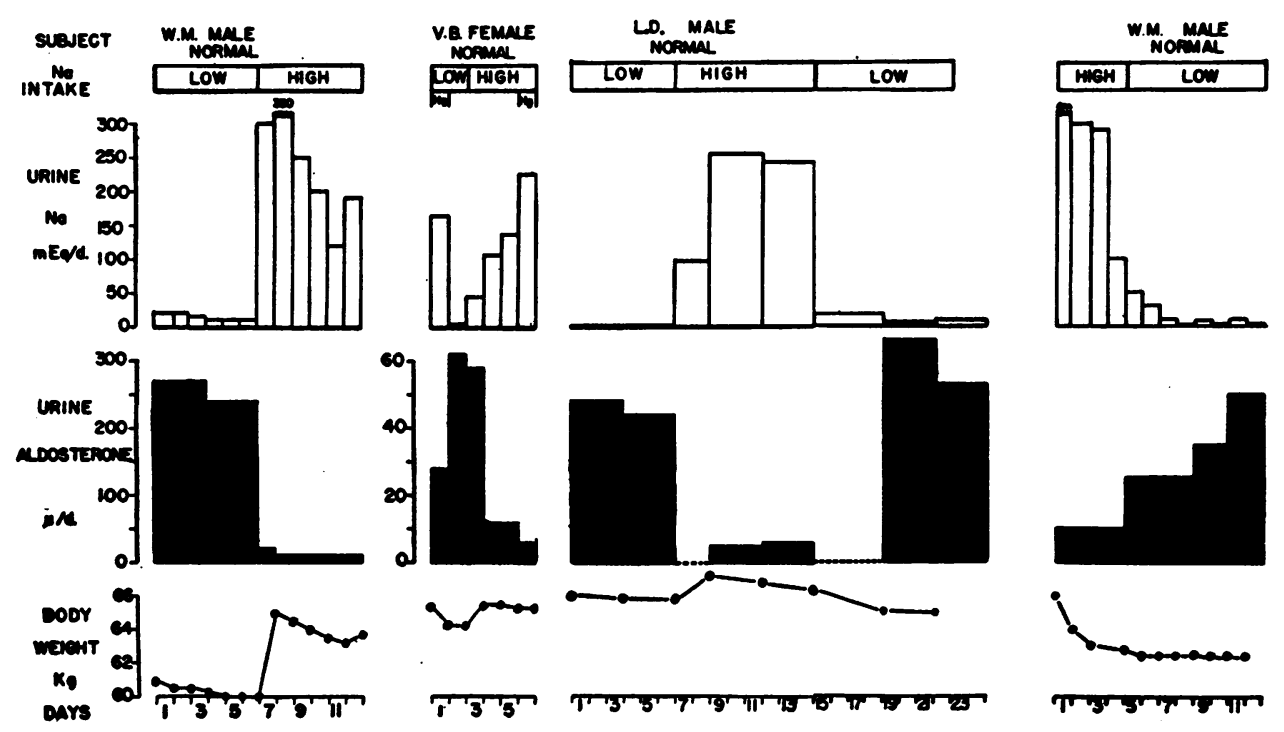

Fig. 1. Sodium Intake, Urinary Sodium and Aldosterone, and Body Weight in Normal Subjects

$\mathrm{Hg}$ indicates mercurial diuretics. Note that in V. B. a mercurial given together with sodium did not affect aldosterone excretion; this was demonstrated in 2 other subjects.

In this and subsequent charts, urinary aldosterone is represented in solid black. When the zero line alone is shown, assays were not done. $\mu$ indicates micrograms.

constant, low sodium diets, the water content of which was estimated to approximate the "insensible loss" of water. Pitressin Tannate in Oil was administered to maintain antidiuresis, and additional water was then administered by mouth. The organism was thus presented simultaneously with an increase of fluid volume and a decrease of serum sodium concentration and osmolality. The results in two subjects are shown in Figures 2 and 3. Those in the other two subjects were substantially the same. Expansion of body fluids with water resulted in gain of weight, hyponatremia, and decreases in urinary aldosterone. In each case there was an increase in urinary sodium excretion and a decrease in urinary potassium excretionphysiological changes one would expect following decreases in aldosterone secretion (10).

When Pitressin was stopped and water loss permitted, aldosterone excretion rose in all cases as urinary sodium excretion fell and urinary potassium excretion rose.

\section{The effect of contraction of body fluids}

If the water loading produced decreases in aldosterone secretion in these subjects through its contribution to body fluid volume, it follows that contraction of body fluids, without sodium deprivation, should lead to a rise in aldosterone secretion. To test this hypothesis, a patient with diabetes insipidus, one with panhypopituitarism, and 5 normal subjects were subjected to dehydration while receiving diets containing moderate amounts of sodium. The organism was thus simultaneously presented with a decrease of fluid volume and an increase of serum sodium concentration and osmolality. Some of the results are shown in Figures $4,5,6$. In the patient with diabetes insipidus, (Figure 4), Pitressin Tannate in Oil was administered at constant dosage during control periods. During experimental periods, (Figure 4, days 4 and 13) the Pitressin was discontinued for 36 hours. There ensued diuresis, loss of weight, hypernatremia and increases in aldosterone excretion. In both instances there was a decrease in urinary sodium excretion and an increase in urinary potassium excretion-physiological changes one would expect following increases in aldosterone secretion (10).

In the other subjects (Figures 5 and 6), the changes were similar, although the degree of dehydration and the resulting rise in aldosterone excretion were quantitatively much less. 


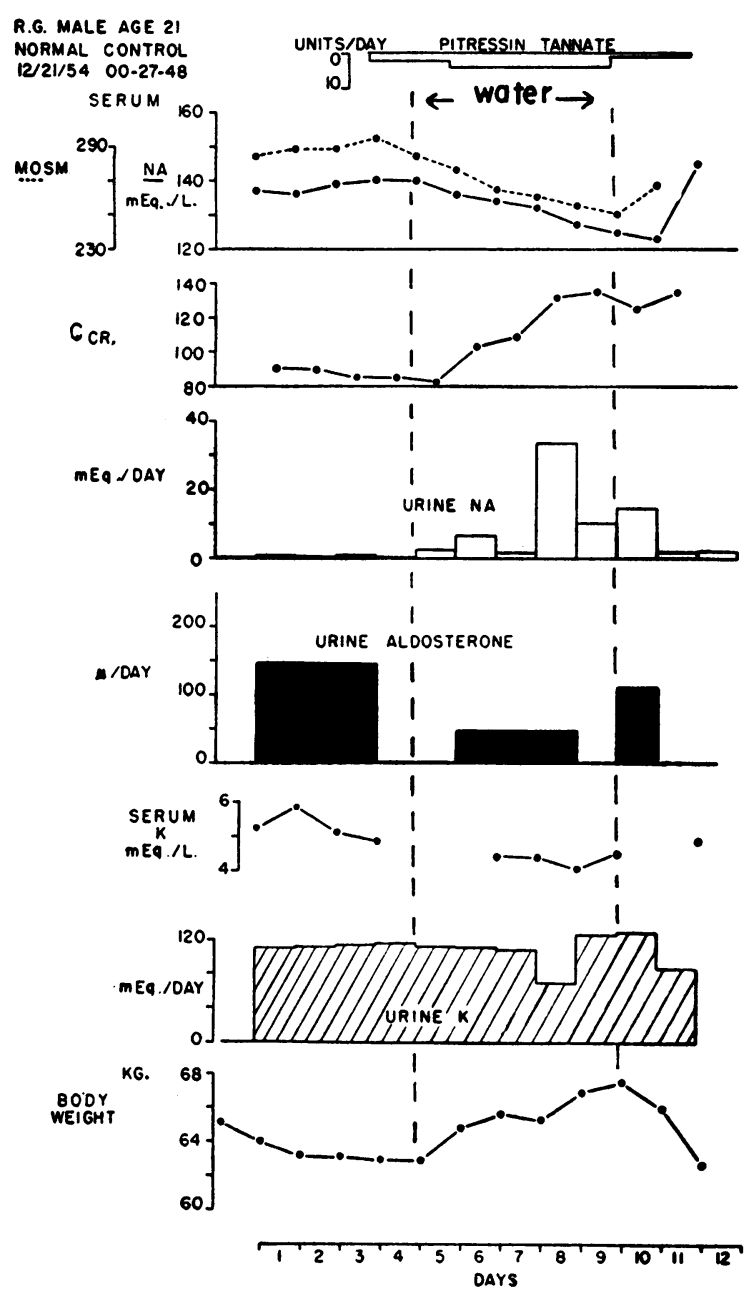

Fig. 2. Serum Sodium, Osmolality and Potassium, Creatinine Clearance, Urine Sodium, Aldosterone and Potassium, and Body Weight in a Normal, SodiUm-Depleted Subject on Low and High Water INTAKES

One to three liters of water were added to the intake on days 5 through 9 . Sodium intake was $9 \mathrm{mEq}$. a day throughout.

\section{The effect of expansion of extracellular fluid volume and simultaneous contraction of intra- cellular fluid volume}

In view of the above observations, and of the reciprocal relationship between aldosterone secretion and the urinary excretion of sodium, chief cation of the extracellular fluid, it is reasonable to suppose that it is the extracellular fluid rather than total body fluid whose volume influences aldosterone secretion. This was tested directly by administering hypertonic saline to four sodium-de- pleted subjects while on a regimen in which the total fluid intake was maintained at or below the "insensible loss." The organism was thus presented simultaneously with an increase of extracellular fluid volume and a decrease of intracellular fluid volume. The results in two studies are shown in Figures 7 and 8; those in the other two were substantially the same. There was no gain (in two cases, indeed, a loss) of body weight, and thus of total body water. In each case there was a fall of aldosterone excretion. In three cases the

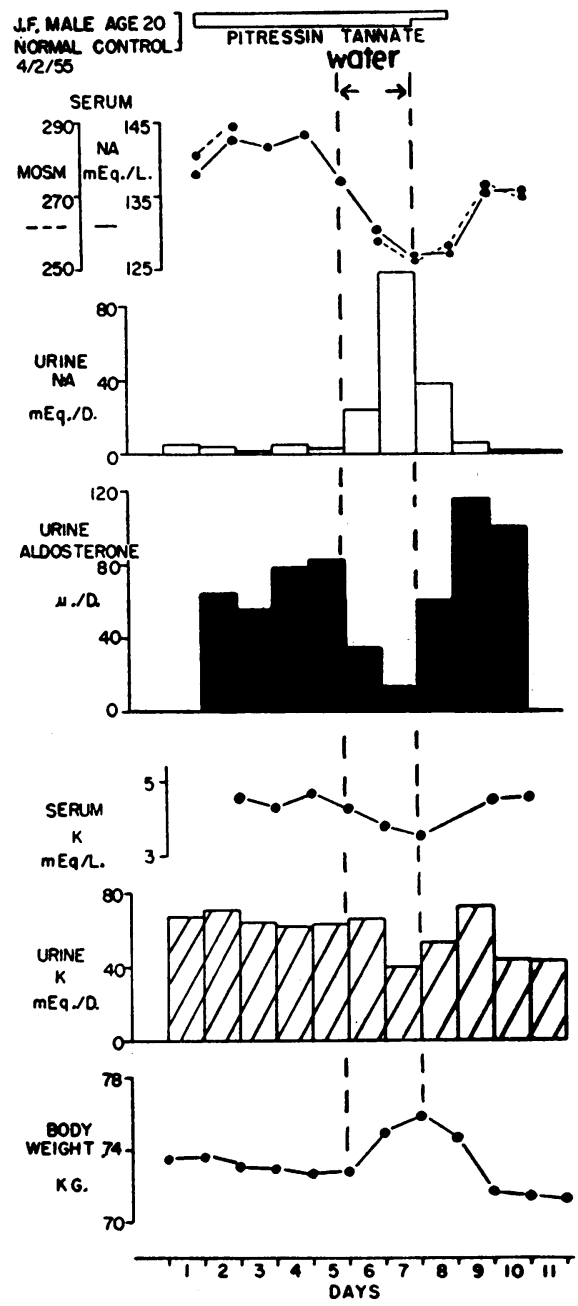

Fig. 3. Serum Sodium, Osmolality and Potassium, Urine Sodium, Aldosterone and Potassium, and Body Weight in a Normal Sodium-Depleted Subject on LoW AND High Water INTAkes

Four liters of water were added to the intake on day 6, and 2 liters on day 7. Data on day 5 were "corrected" for loss of urine with creatinine data. Sodium intake was $10 \mathrm{mEq}$. a day throughout. 


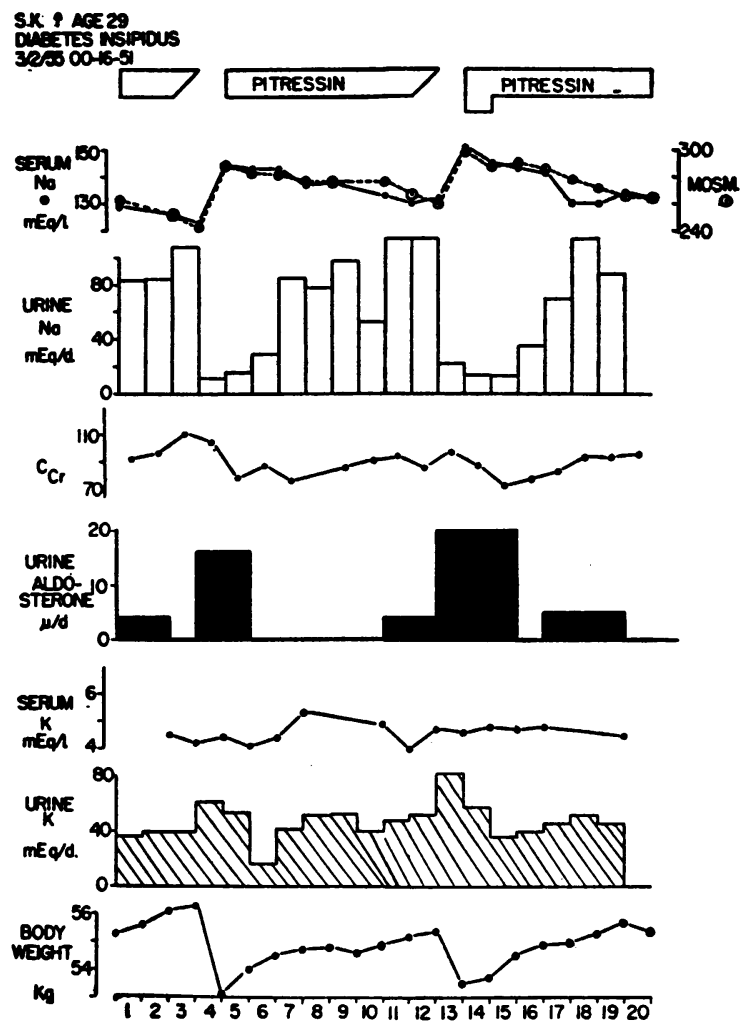

Fig. 4. Serum Sodium, Osmolality and Potassium, Creatinine Clearance, and Urine Sodium, Aldosterone and Potassium in a Subject with Diabetes InSipidus Dehydrated by Withdrawal of Pitressin.

Sodium intake was $100 \mathrm{mEq}$. a day throughout.

magnitude of the expansion of extracellular volume was estimated from "chloride space" calculations. It was $1.7,3$, and 2.2 per cent of body weight.

\section{$V$. Comparison of the effect of total body water} loss with that of extracellular fluid loss in the same subject

In four subjects the effect of simple dehydration was compared, on an otherwise identical regimen, with that of predominantly "extracellular dehydration" (12) produced with mercurial diuretics. Such a comparison is shown in Figure 6. Table I shows a comparison of the total weight loss, the calculated extracellular fluid loss, and the rise in urinary aldosterone in 4 subjects in whom such direct comparisons were made. As noted above, the mercurial diuretics produced no changes in serum sodium concentration. It is apparent that changes in total body water were less effective in influencing aldosterone excretion than much smaller changes in extracellular fluid volume.

\section{DISCUSSION}

These studies show decreases of urinary aldosterone with expansion of extracellular fluid vol-

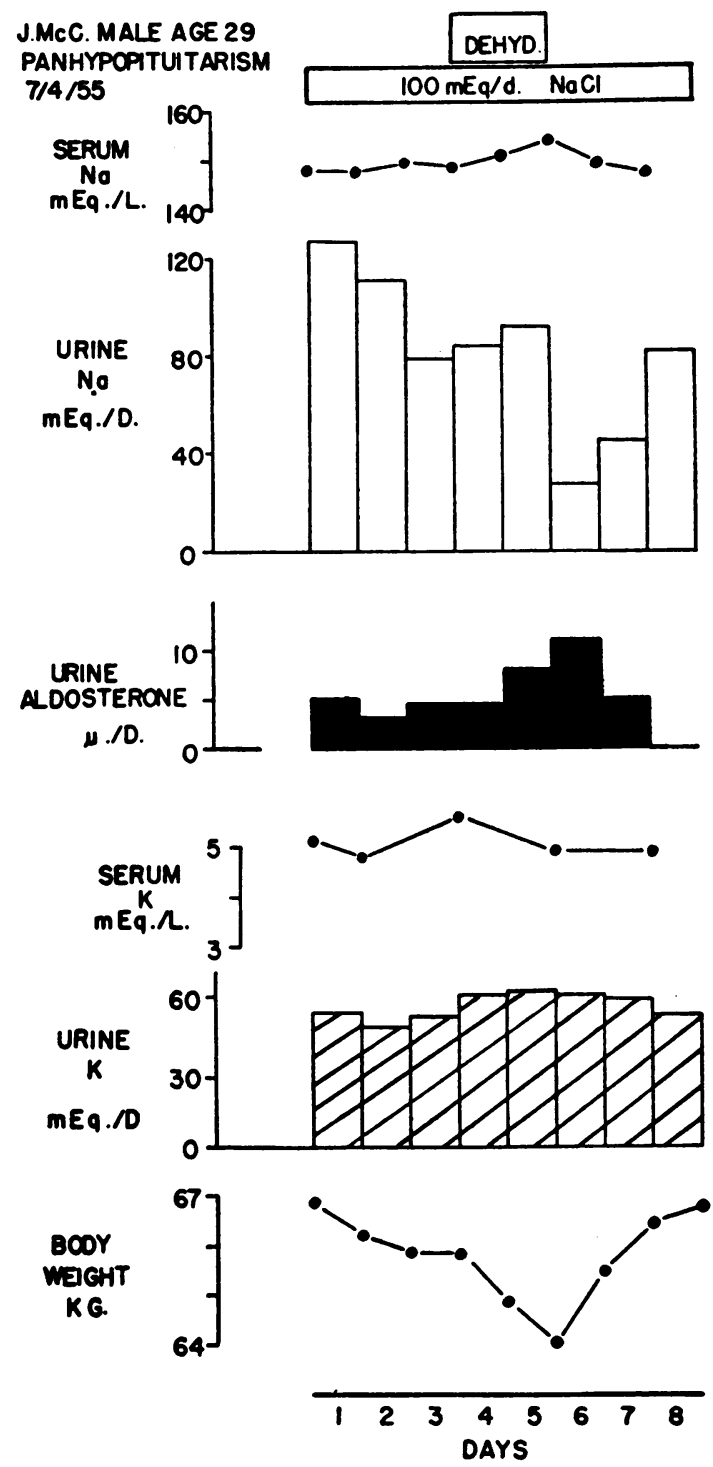

Fig. 5. Serum Sodium and Potassium, Urine Sodium, Aldosterone and Potassium, and Body Weight in a Subject with Panhypopituitarism on Normal and Low ("Dehyd.") Water Intakes

Sodium intake was $100 \mathrm{mEq}$. a day throughout.

A very high aldosterone excretion at the start of day 6 is indicated by the high "average" for this day despite starting hydration. 


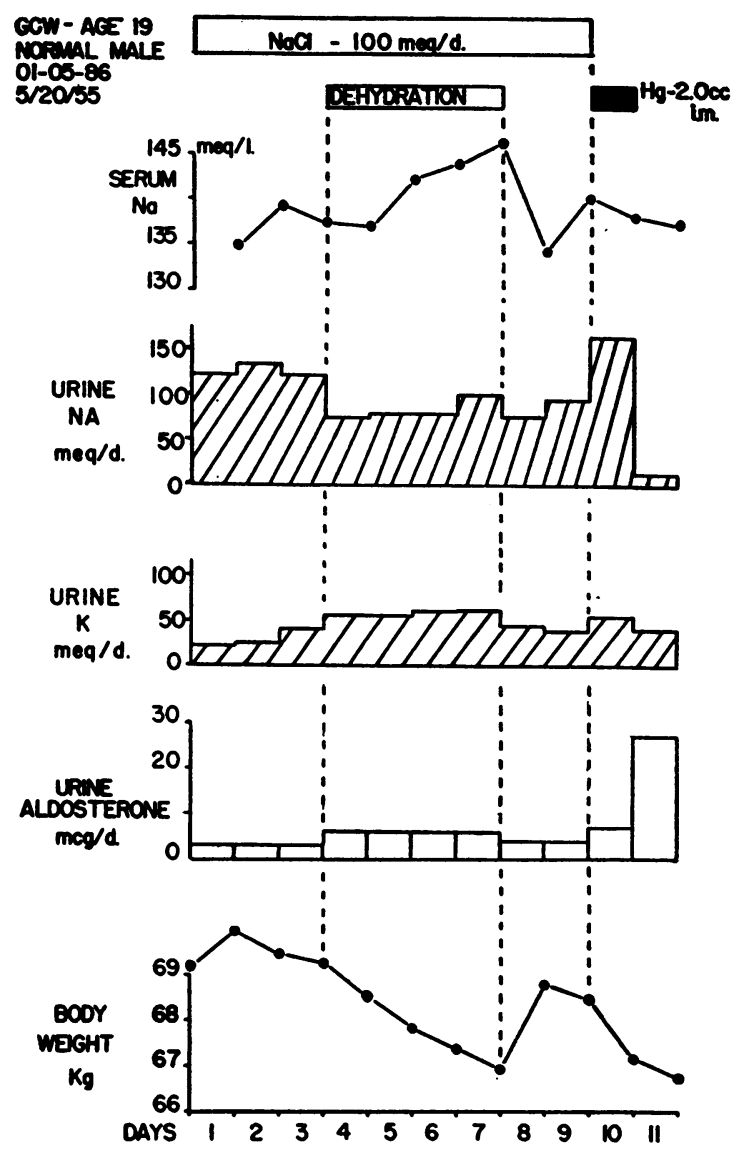

Fig. 6. Serum Sodium, Urine Sodium, Potassium and Aldosterone and Body Weight in a Normal SubJECt on Normal and Low Water Intakes and after MERCUHYDRIN

Sodium intake was $9 \mathrm{mEq}$. per day on days 10 and 11 .

ume. When the expansion is produced with water alone, intracellular water increases pari passu with extracellular water (13) and intracellular tonicity must decrease as the extracellular fluid tonicity is lowered. When the expansion is produced with normal saline the changes in intracellular water and tonicity are minimal (14) and no changes of extracellular fluid tonicity are seen. When the expansion is produced with hypertonic saline while thirsting, intracellular water must decrease, and intracellular tonicity increase, as water leaves the cells to enter the extracellular compartment.

Conversely, increases of urinary aldosterone were shown with contraction of extracellular fluid volume. When the contraction is produced by simple dehydration, intracellular water decreases and intracellular tonicity must increase, as the extracellular fluid tonicity is increased (14). When the contraction is produced by a mercurial diuretic, the changes in intracellular water and tonicity are minimal (12) and no changes of extracellular fluid tonicity are seen.

It is thus apparent that the changes in urinary aldosterone are not dependent upon either the volume or the tonicity of intracellular fluid, or upon the sodium concentration or tonicity of the extracellular fluid. In the Pitressin ${ }^{\circledR}$-and-water studies and in the dehydration studies, they are clearly not dependent upon total body sodium. In all cases they do follow reciprocal changes in extracellular fluid volume.

It has been assumed that urinary aldosterone excretion reflects blood levels of aldosterone. Much indirect evidence supports this assumption for subjects without renal impairment. Crystalline aldosterone produces a decrease in urinary
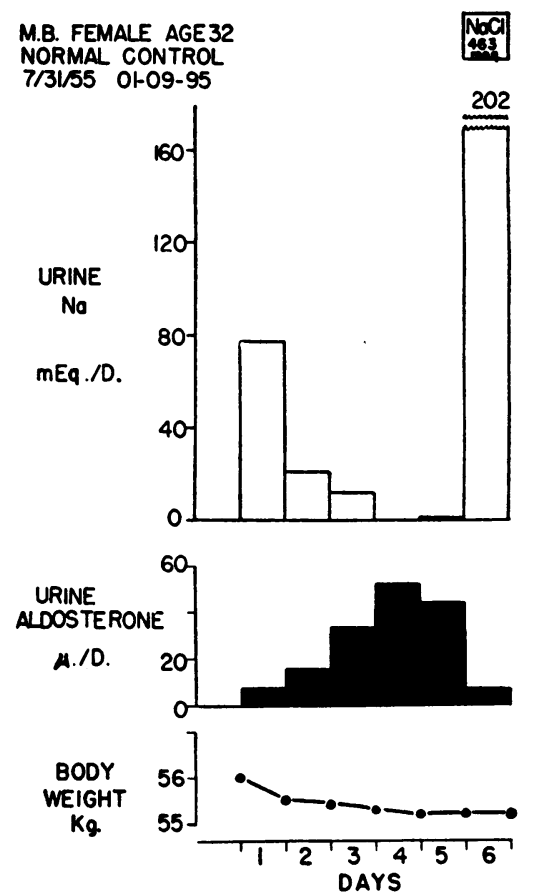

Fig. 7. Urinary Sodium and Aldosterone, and Body Weight in a Normal Subject Who Recerved Hypertonic Saline Intravenously on Restricted WATER INTAKe

Note that aldosterone fell with extracellular fluid expansion without gain in weight or total body water.

Oral sodium intake was $9 \mathrm{mEq}$. a day throughout. On day 4, $463 \mathrm{mEq}$. of 3.0 per cent saline were given intravenously. 
sodium excretion and an increase in urinary potassium excretion $(3,10,15)$. Thus the metabolic data should supply evidence as to whether the changes of urinary aldosterone reflect similar changes in serum aldosterone levels, and are not results of changes in renal clearance of the steroid. When body fluids were expanded with water (Figures 2 and 3), the decreases of urinary aldosterone were always accompanied by increases in urinary sodium and decreases in urinary potassium. When body fluids were contracted as a result of water loss alone (Figures 4,5 , and 6 ), the increases of urinary aldosterone were accompanied by decreases in urinary sodium; where the contraction was quantitatively greatest (Figure 4) there were marked increases in urinary potassium. This provides strong presumptive evidence that the urinary values do in fact reflect serum levels. In further support of this assumption is the fact that endogenous creatinine clearances indicated that increases in glomerular filtration rate accompanied the decreases in urinary aldosterone in the "expansion" studies (Figures 2 and 3 ) whereas decreases in filtration rate accompanied the increases in urinary aldosterone in the "contraction" studies (Figure 4).

In a previous study (16) it was shown that expansion of body fluids with water produced urinary loss of sodium, and it was suggested that this loss was in part a homeostatic response to the increase of body fluid volume. Increases of glomerular filtration rate accompanied the sodium loss, however, and a direct measure of aldosterone excretion was not then available. In that study, expansion of body fluid volume was accompanied by a fall in urinary potassium excretion during the period of expansion in all of the normal subjects but one-a finding in accord with the view that

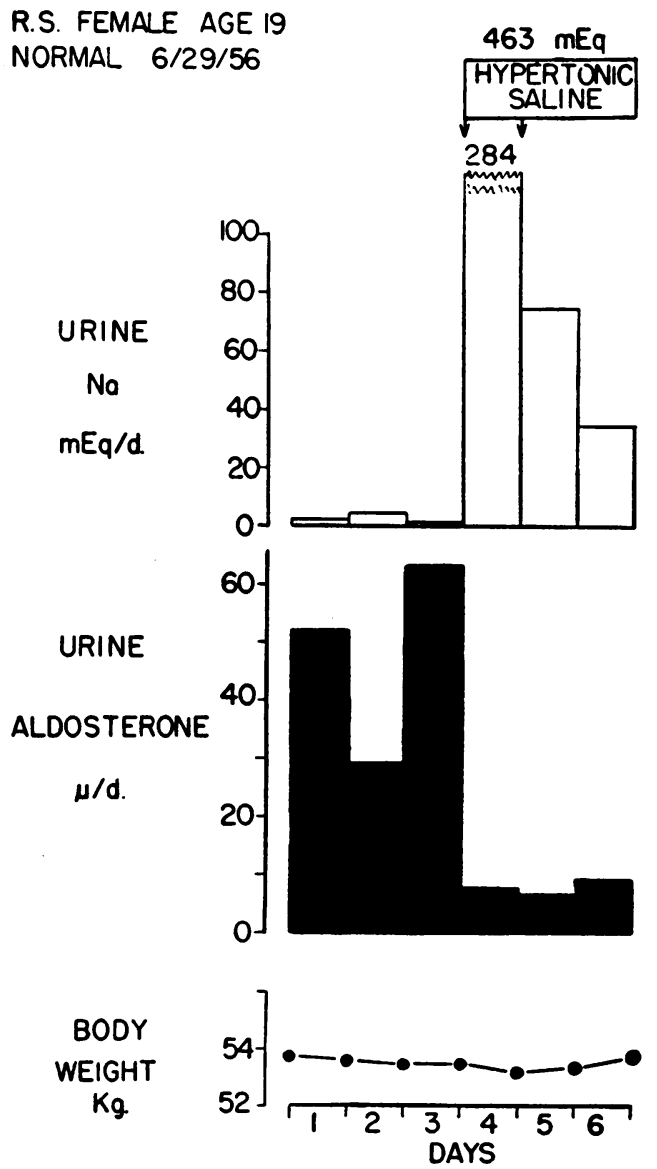

Fig. 8. Urinary Sodium and Aldosterone and Body Weight in a Normal Subject Who Received Hypertonic Saline Intravenously on Restricted Water INTAKE

Note that aldosterone fell with extracellular expansion without gain in weight or total body water. Oral sodium intake was $9 \mathrm{mEq}$. a day throughout.

there were indeed decreases in circulating aldosterone during expansion.

It is assumed that changes in circulating aldosterone reflect changes in aldosterone secretion,

TABLE I

Comparison of the effect, in the same individual on the same regimen, of simple dehydration with that of "extracellular dehydration" on aldosterone excretion

\begin{tabular}{|c|c|c|c|c|c|c|c|c|c|c|}
\hline \multirow[b]{3}{*}{ Subject } & \multirow{3}{*}{$\begin{array}{c}\text { Wt. loss } \\
\boldsymbol{K}_{\boldsymbol{g}} \text {. }\end{array}$} & \multicolumn{2}{|c|}{ Dehydration } & & & \multirow{3}{*}{$\begin{array}{c}\text { Wt. loss }_{\text {K. }} \\
K_{\mathbf{g} .}\end{array}$} & \multicolumn{2}{|c|}{ "ECF dehydration" } & & \\
\hline & & \multirow{2}{*}{ B.W. } & \multirow{2}{*}{$\begin{array}{c}\text { "Chloride } \\
\text { space" } \\
\text { loss } \\
L .\end{array}$} & \multicolumn{2}{|c|}{$\begin{array}{c}\text { Aldosterone } \\
\mu g m . / d a y\end{array}$} & & \multirow{2}{*}{$\begin{array}{l}\% \text {. } \\
\text { B.w. }\end{array}$} & \multirow{2}{*}{$\begin{array}{c}\text { "Chloride } \\
\text { space" } \\
\text { loss } \\
L .\end{array}$} & \multicolumn{2}{|c|}{$\begin{array}{c}\text { Aldosterone } \\
\mu \mathrm{gm} . / \text { day }\end{array}$} \\
\hline & & & & Initial & Final & & & & Initial & Final \\
\hline $\begin{array}{l}\text { J. McC. } \\
\text { V. B. } \\
\text { S. Z. } \\
\text { G. W. }\end{array}$ & $\begin{array}{l}1.79 \\
1.32 \\
1.93 \\
2.29\end{array}$ & $\begin{array}{l}2.7 \\
2.0 \\
3.0 \\
3.3\end{array}$ & $\begin{array}{c}0.47 \\
0.50 \\
0.36 \\
0\end{array}$ & $\begin{array}{c}4.5 \\
12 \\
3 \\
3\end{array}$ & $\begin{array}{r}11 \\
21 \\
9 \\
6\end{array}$ & $\begin{array}{l}0.32 \\
1.13 \\
1.00 \\
1.73\end{array}$ & $\begin{array}{l}0.5 \\
1.7 \\
1.6 \\
2.5\end{array}$ & $\begin{array}{l}1.15 \\
1.81 \\
1.53 \\
2.06\end{array}$ & $\begin{array}{r}3 \\
27 \\
9 \\
4\end{array}$ & $\begin{array}{l}19 \\
62 \\
17 \\
26\end{array}$ \\
\hline
\end{tabular}




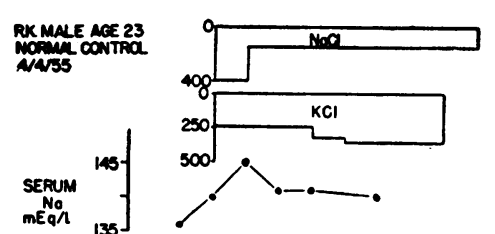

$\mathrm{mEq} / \mathrm{d}$.
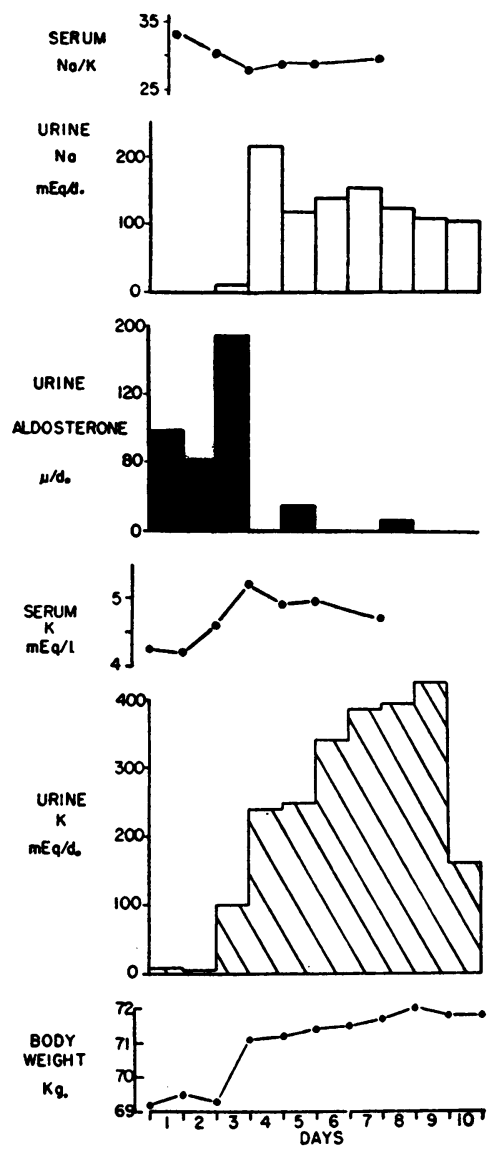

Fig. 9. Serum Sodium, Potassium and Sodium-toPotassium Ratio and Urinary Sodium, Aldosterone and Potassium in a Normal Subject on Balance Regimen upon Loading with Potassium and With Sodium and Water Simultaneously

A single mercurial diuretic had previously been given to produce sodium depletion, and an ion exchange resin fed for one day to produce potassium depletion. Note the fall in aldosterone excretion despite the rise in serum potassium and the fall in serum sodium-to-potassium ratio. The data suggest substantial rise in total body potassium during "loading."

although the possibility that they reflect reciprocal changes in its destruction cannot be rigidly excluded.

It has been shown that potassium loading may produce increases, and potassium depletion decreases, in aldosterone secretion $(1,2,17)$, even when such procedures do not result in reciprocal changes in sodium balance (2). The mechanism by which potassium exerts these effects is obscure. The changes in aldosterone secretion described in the present study could be shown to occur without significant changes in a) serum potassium, b) the ratio of serum sodium to serum potassium, or c) total body potassium. In four cases, rises of aldosterone secretion were produced by mercurials in the absence of dietary potassium, in contrast to the findings of Laragh and Stoerk (17). In the study shown in Figure 9 , very large increases in serum potassium and presumably in total body potassium, and a striking decrease in the serum "sodium-to-potassium ratio" were produced with potassium loading, but a concomitant rise in extracellular fluid volume was induced, and aldosterone excretion fell. Similar results were obtained in two other subjects. Thus the effects of fluid volume changes on aldosterone secretion are not mediated by any demonstrable changes in potassium metabolism.

The present study shows changes in aldosterone secretion which paralleled, and thus did not tend to oppose, changes in serum sodium concentration -that is, decreases in aldosterone secretion could be induced in spite of hyponatremia and increases in spite of hypernatremia. The question arises as to whether changes in serum sodium concentration, per se, ever give rise to compensatory changes in aldosterone secretion. Our studies give little support to such a mechanism. (Indeed, when effects on renal hemodynamics are excluded there appears to be no evidence [18] that sodium conservation can be induced by hyponatremia, or sodium loss by hypernatremia.) This adrenal cortical independence of concentration is, of course, in contrast to the dependence (19) of the supraoptico-hypophyseal system on effective serum osmolality. We suggest that the normal control of sodium and water homeostasis depends on a dual "feed-back" mechanism, as illustrated in Figure 10 , where aldosterone is shown to produce an increase in serum sodium concentration, which results (through decrease in water excretion mediated by antidiuretic hormone and/or through increase in water intake) in a rise of extracellular fluid volume. Some function of the volume increase then serves to inhibit aldosterone secretion. We have no evidence relating to the mechanism 


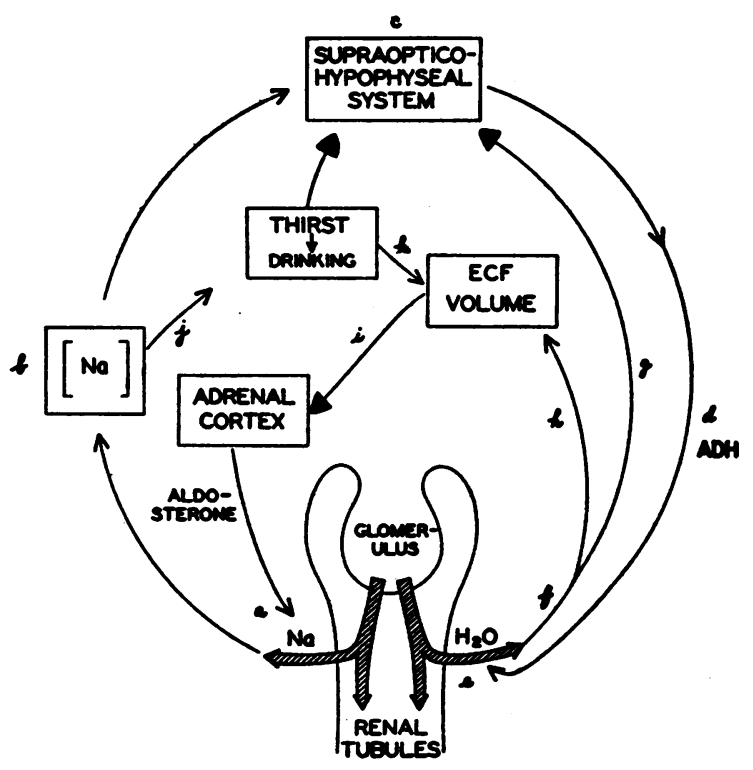

Fig. 10. A Simplified Schema to Represent Normal Control of Sodium and Water Homeostasis

Aldosterone increases tubular sodium transport (a) thus tending to increase serum solute concentration (b). This stimulates the supraoptico-hypophyseal system (c) to produce antidiuretic hormone (ADH) (d) which promotes water reabsorption (e). The water so reabsorbed (f) lowers the serum solute concentration ( $g$ ), thus inhibiting further $A D H$ output, but also contributes to ECF volume $(h)$. Some function of ECF volume tends to inhibit further aldosterone output (i).

Alternatively, increase of serum solute concentration (b) may lead to thirst ( $j$ ) and thus directly to an increase in ECF volume $(k)$. The sodium intake is assumed to be constant.

The proposed schema omits reference to the effects of volume changes per se on $\mathrm{ADH}$ secretion $(20,21)$ as not germane to the present material. It also ignores renal hemodynamic changes.

$$
\begin{aligned}
& \rightarrow=\text { stimulation } \\
& \Rightarrow=\text { inhibition }
\end{aligned}
$$

by which effects of volume changes may be transmitted to the adrenal cortex.

It has been shown $(5,22-26)$ that nephrosis, cirrhosis with ascites, and cardiac failure are characterized by aldosterone secretion in excess of normal in spite of increases in extracellular fluid volume. The present studies do not, of course, explain the pathological physiology of aldosterone secretion in these diseases. It has been found (22), however, that even when these conditions are present, some function of extracellular fluid volume can still exert some control over the amount of aldosterone secreted. If the "ef- fective" volume resides within the vascular compartment (3) the stimulus to aldosterone secretion in nephrosis and cirrhosis with ascites may be a result of loss of such volume into the tissues and the abdominal cavity, respectively.

Since sodium restriction regularly produces elevated levels of circulating aldosterone it might be expected to produce potassium depletion, a cardinal finding in cases in which excessive aldosterone arises from tumors $(27,28)$. An analogous question arises in regard to these clinical states (cardiac failure, cirrhosis with ascites, and nephrosis) in which large amounts of urinary aldosterone have been repeatedly found $(5,22-26)$ but in which potassium depletion is an exceptional finding. For the disease states this has been explained (29) on the assumption that steroids can promote potassium excretion only by accelerating renal tubular exchange of potassium for sodium at a distal site. If, owing to complete reabsorption more proximally, virtually no sodium is available for such an exchange, aldosterone cannot increase urinary potassium (3).

The frequent finding in the cardiac and cirrhotic patient, as in the sodium-depleted normal subject, of essentially sodium-free urine is consistent with such an explanation; in all these conditions the efficiency of sodium reabsorption may be enhanced, not only by the larger amounts of circulating aldosterone, but also by decreases of filtration rate $(30,31)$ and thus of filtered sodium. In the patients with aldosterone-producing tumors normal filtration rates have been reported (27, 28). It appears likely that rigid sodium restriction would prevent the potassium loss in such patients (3). Furthermore, in view of the fact that patients with primary aldosteronism have been reported to excrete relatively little aldosterone (27, 28) compared to salt-depleted normal subjects or patients with cardiac failure and cirrhosis, it is likely that cases will be found in which, under the influence of much larger amounts of aldosterone, sodium retention will be almost quantitative, and edema, rather than alkalosis and potassium loss, will be the cardinal manifestation.

\section{SUMMARY AND CONCLUSIONS}

Studies were carried out in man to define the role of fluid volume in controlling aldosterone secretion. 
It was shown that changes in aldosterone secretion could be effected by changes in body fluid volume, independent of changes in extracellular or intracellular ion or water concentrations.

Decreases of aldosterone secretion were produced by measures which increased extracellular fluid volume, regardless of whether intracellular water was increased (by administration of Pitressin and water), decreased (by administration of hypertonic saline) or left unchanged (by administration of normal saline). Serum sodium concentration and osmolality fell, rose, and remained unchanged, respectively, in the three types of study.

Increases of aldosterone secretion were produced by measures which decreased extracellular fluid volume, regardless of whether intracellular water was decreased (by dehydration) or left unchanged (by administration of mercurial diuretics). Serum sodium concentration and osmolality rose, and remained unchanged, respectively, in the two types of experiment.

Changes of circulating and total body potassium could be excluded as mediators of the volume control of aldosterone secretion.

\section{REFERENCES}

1. Liddle, G. W., Bartter, F. C., Duncan, L. E., Jr., Barber, J. K., and Delea, C., Mechanisms regulating aldosterone production in man. J. Clin. Invest., 1955, 34, 949.

2. Bartter, F. C., Proceedings of the Laurentian Hormone Conference, 1955. Discussion of paper by Dr. J. A. Luetscher. Recent Progress in Hormone Research, 1956, In Press.

3. Bartter, F. C., The role of aldosterone in normal homeostasis and in certain disease states. Metabolism, 1956, 5, 369.

4. Bartter, F. C., Liddle, G. W., Duncan, L. E., and Delea, C., The role of extracellular fluid volume in the control of aldosterone secretion in man. J. Clin. Invest., 1956, 35, 688.

5. Luetscher, J. A., Jr., and Johnson, B. B., Observations on the sodium-retaining corticoid (aldosterone) in the urine of children and adults in relation to sodium balance and edema. J. Clin. Invest., 1954, 33, 1441.

6. Luetscher, J. A., Jr., and Axelrad, B. J., Increased aldosterone output during sodium deprivation in normal men. Proc. Soc. Exper. Biol. \& Med., 1954, 87, 650.

7. Van Slyke, D. D., and Hiller, A., Application of Sendroy's iodometric chloride titration to protein-containing fluids. J. Biol. Chem., 1947, 167, 107.
8. Bowman, R. L., Trantham, H. V., and Caulfield, P. A., An instrument and method for rapid, dependable determination of freezing-point depression. J. Lab. \& Clin. Med., 1954, 43, 310.

9. International Critical Tables of Numerical Data, Physics, Chemistry and Technology. New York, McGraw-Hill Book Company, Inc., 1928, Volume IV, p. 258.

10. Liddle, G. W., Cornfield, J., Casper, A. G. T., and Bartter, F. C., The physiological basis for a method of assaying aldosterone in extracts of human urine. J. Clin Invest., 1955, 34, 1410.

11. Beck, J. C., Dyrenfurth, I., Giroud, C., and Venning, E. H., Observations on the regulatory mechanisms of aldosterone secretion in man. Arch. Int. Med., $1955,96,463$.

12. Blumgart, H. L., Gilligan, D. R., Levy, R. C., Brown, M. G., and Volk, M. C., Action of diuretic drugs; I. Action of diuretics in normal persons. Arch. Int. Med., 1934, 54, 40.

13. Leaf, A., Chatillon, J. Y., Wrong, O., and Tuttle, E. P., Jr., The mechanism of the osmotic adjustment of body cells as determined in vivo by the volume of distribution of a large water load. J. Clin. Invest., 1954, 33, 1261.

14. Gamble, J. L., Companionship of water and electrolytes in the organization of body fluids. Lane Medical Lectures, 1949. Stanford, Stanford University Press, 1951.

15. Desaulles, P., Tripod, J., and Schuler, W., Wirkung von Elektrocortin auf die Elektrolyt- und Wasserausscheidung in Vergleich zu Desoxycorticosteron. Schweiz. med. Wchnschr., 1953, 83, 1088.

16. Leaf, A., Bartter, F. C., Santos, R. F., and Wrong, O., Evidence in man that urinary electrolyte loss induced by pitressin is a function of water retention. J. Clin. Invest., 1953, 32, 868.

17. Laragh, J. H., and Stoerk, H. C., On the mechanism of secretion of the sodium-retaining hormone (aldosterone) within the body. J. Clin. Invest., 1955, 34, 913.

18. Smith, H. W., The Kidney: Structure and Function in Health and Disease. New York, Oxford University Press, 1951.

19. Verney, E. B., The antidiuretic hormone and the factors which determine its release. Proc. Roy. Soc., London, s. B., 1947, 135, 25.

20. Leaf, A., and Mamby, A. R., An antidiuretic mechanism not regulated by extracellular fluid tonicity. J. Clin. Invest., 1952, 31, 60.

21. Schwartz, W. B., Bennett, W., Curelop, S., and Bartter, F. C., Studies on the mechanism of a sodium-losing syndrome in two patients with mediastinal tumors. J. Clin. Invest., 1956, 35, 734.

22. Duncan, L. E., Jr., Liddle, G. W., and Bartter, F. C., The effect of changes in body sodium on extracellular fluid volume and aldosterone and sodium excretion by normal and edematous men. J. Clin. Invest., 1956, 35, 1299. 
23. McCall, M. F., and Singer, B., Studies in nephrosis : Chemical corticoids, salt-retaining factor, and effect of ACTH. J. Clin. Endocrinol. \& Metab., 1953, 13, 1157.

24. Pechet, M. M., Duncan, L. E., Jr., Liddle, G. W., and Bartter, F. C., Studies on a salt retaining factor prepared from human urine. J. Clin. Invest., 1954, 33, 957.

25. Gordon, E. S., The role of aldosterone in congestive heart failure. J. Lab. \& Clin. Med., 1955, 46, 820.

26. Liddle, G. W., Duncan, L. E., Jr., and Bartter, F. C., Dual mechanism regulating adrenocortical function in man. Am. J. Med., 1956, In Press.

27. Conn, J. W., and Louis, L. H., Primary aldosteronism, a new clinical entity. Ann. Int. Med., 1956, 44, 1.
28. Mader, I. J., and Iseri, L. T., Spontaneous hypopotassemia, hypomagnesemia, alkalosis and tetany due to hypersecretion of corticosterone-like mineralocorticoid. Am. J. Med., 1955, 19, 976.

29. Howell, D. S., and Davis, J. O., Relationship of sodium retention to potassium excretion by the kidney during administration of desoxycorticosterone acetate to dogs. Am. J. Physiol., 1954, 179, 359.

30. Merrill, A. J., Edema and decreased renal blood flow in patients with chronic congestive heart failure: Evidence of "forward failure" as the primary cause of edema. J. Clin. Invest., 1946, 25, 389.

31. Leslie, S. H., Johnson, B., and Ralli, E. P., Renal clearances in patients with cirrhosis of the liver, with and without ascites. J. Clin. Endocrinol., $1949,9,682$. 